\title{
Alcohol Use in Later Life - older people's perspectives
}

\author{
Lizzie Ward, \\ Research Fellow, Social Science Policy and Research Centre, University of Brighton \\ Marian Barnes \\ Professor of Social Policy, School of Applied Social Science, University of Brighton \\ Beatrice Gahagan \\ Senior Manager, Age Concern Brighton, Hove and Portslade
}

Quality in Ageing and older Adults, vol 12 (4) 2011

\section{Abstract \\ Purpose}

There has been increasing recognition that alcohol may be a source of problems for older people. This has been reflected in the increase in alcohol-related hospital admissions for people over 65 . Although a neglected area in policy and research within the UK, studies from health and social care practice have drawn attention to the complexity of the issues for practitioners. This paper reports on qualitative research which aimed to generate a wider evidence base by exploring the circumstances in which older people drink, the meaning that drinking alcohol has for them and its impact, acknowledging that this can be a pleasurable and positive experience, as well as something that can have adverse health, financial, personal and interpersonal impacts.

\section{Design/methodology/approach}

A major challenge of the research, given the sensitive nature of the topic, was how to approach older people and ask about their experiences of alcohol use. A participatory methodology was developed in which older people were actively involved in designing and carrying out the research. Older co-researchers conducted 21 individual interviews and 3 focus groups with a diverse range of older research participants from different backgrounds and circumstances.

\section{Findings}

The findings indicate that participants engaged in different drinking styles which connected to complex relationships between individual biographies, personal circumstances and external factors. Recommendations for practice and policy development are made on the basis of these.

\section{Originality/value}


This is a sensitive topic involving stigma and practitioners have highlighted issues around lack of training and appropriate referral services as well as difficulties in approaching the topic with older people. In addition, there is a tension in the drive to promote service users' rights to have choices and the question of whether to intervene if those choices involve risky behaviour. Even less is known about the perspectives of older people themselves and more research is needed to understand the social, cultural and economic contexts of older people's drinking behaviour.

\section{Key Words}

Alcohol, drinking practices, biographies, participatory research

\section{Paper Type}

Research report

\section{Introduction}

Until recently the problematic use of alcohol has been predominantly associated with young people and binge drinking. Amongst health and social care professionals however, there is increasing recognition that alcohol may be a source of problems for older people. NHS data show that alcohol-related admissions for those over 65 had risen by two thirds between 2003 and 2007 (NHS Information Centre, 2008; Triggle, 2009) and alcohol trends published by the Joseph Rowntree Foundation noted an increase in drinking amongst older age groups (Smith and Foxcroft, 2009). Yet, very little is known about older people's perspectives on alcohol use in later life.

There have been a number of studies which have focused on the extent to which older people who receive services may have a problem with alcohol, the difficulties in recognising problem drinking in older service users and how health and social care practitioners should respond (Herring and Thom, 1997a, b; Klein and Jess, 2002; Simpson et al., 1994). Findings from these studies indicate:

- The prevalence of problematic drinking is unclear due to the sensitivity of the topic and stigma leading to under-reporting.

- The lack of awareness of the possibility of alcohol problems, in part due to medication and other health conditions masking the effects of alcohol consumption.

- A lack of appropriate referral agencies for treatment.

- Reluctance among professionals to broach the topic directly with service users. 
- A dilemma between awareness of the need for support where a person is vulnerable and a reluctance to judge.

- A tension between rights and risks - the wish to respect privacy, autonomy and choices even if this puts the older person at risk.

- A lack of specialist training, uncertainty about how to include problematic alcohol use in the context of assessment and in the management of problematic use in residential settings.

None of these issues which relate specifically to older people's alcohol use feature in the policy response to recent increases in alcohol-related hospital admissions. The focus of the Alcohol Harm Reduction Strategy for England (Prime Minister's Strategy Unit, 2004) and the subsequent Safe Sensible Social: The next steps in the National Alcohol Strategy (Department of Health, 2007) is primarily younger people's drinking and tackling alcohol-related disorder in towns and city centres. The White Paper Choosing Health: Making Healthier Choices Easier (Department of Health, 2004) adopts an individualistic response to the issue focusing on health promotion and behaviour change. Thus individuals are encouraged to adopt 'healthy behaviour' in relation to drinking and the practice response is based in social marketing, brief interventions and one-to-one advice designed to achieve measurable behaviour change targets .

The lack of attention to older people's drinking habits is mirrored within UK academic literature. Studies rarely include people over 74 and those that do are firmly located in a bio-medical framework and focus on the potential harm of alcohol consumption on physical and mental health in later life (Johnson, 2000; Peters et al., 2008). Although there is an increasing body of literature within the health promotion and health education arena, little attention has been paid to social, cultural and economic factors affecting behaviour, or to the influence of social circumstances over the life course (Clough et al., 2004; Davidson and Ginn, 2005). A review by Plant and Plant (2008) confirms that despite a long standing interest in the topic within gerontology, there has been very little research carried out in the UK. Drawing on international research (mostly from the US) to look at trends and highlight the implications for policy and practice in the UK, Plant and Plant conclude that although the extent of alcohol problems amongst older people is unclear it is likely, given an increasingly ageing population, that more alcohol services for older people are going to be needed in the future.

More research is needed to understand older people's drinking behaviour in the context of social, cultural and economic circumstances; the extent to which drinking may be related to the experience of ageing and the ways in which this may vary across gender, class, ethnicity, sexuality and place. The study we report on here 
attempts to respond to this lacuna by exploring the circumstances in which older people drink and the meaning of alcohol in their lives.

\section{Methods}

Our objective of understanding what alcohol use means to older people led us to adopt a participatory research approach in which older people were not only 'active subjects' but also co-researchers (Barnes and Taylor, 2007). We recruited four older people with whom we worked to design and conduct the research. They carried out interviews with older people. We also recruited a reference group comprising five other older people to enable us to draw on wider views and experiences about the topic and how we should approach it. They worked alongside a steering group comprising officers from local agencies who had formed a partnership to promote and support this research. Full details of our approach to working with older people can be found in the project report (Ward et al., 2008).

Discussion within the research team and the steering and reference groups confirmed that the approach should not be to start from assumptions that using alcohol was necessarily a 'problem', and that the focus of the study should not be older people already in contact with services because of problematic alcohol use. We recognised that drinking may be pleasurable in its own right, a means of sustaining social contact, and that it might be used in response to loss. In none of these circumstances would it be helpful to refer to the abuse or misuse of alcohol. Our aim was to enable older people to speak about their experiences of drinking in ways that made sense to them and to construct their own ideas about the place of alcohol in their lives, rather than responding to pre-defined assumptions about, for example, recommended weekly limits in terms of units of consumption.

This affected decisions about study participants. The aim was to identify people who regularly drink alcohol for whom it may, or may not be a problem. Recruitment was challenging because of the sensitive nature of the topic, and because there is no obvious 'population' from which to sample. After discussion with the co-researchers and reference group we agreed a project title - 'Cheers!? A project about older people and alcohol' - and images to be used on a flyer to recruit participants. This was distributed through the steering group member's networks, sheltered housing schemes, day centres, community projects, residents' newsletters and Age Concern's database. The university researcher visited sheltered housing schemes during coffee mornings and residents' meetings to talk about the research and explain what an interview would involve. She also met with staff who worked with older people in day centres and community outreach to ask for their help in publicising the flyer within their work settings. 
Twenty one people were recruited for one-to-one interviews. Our aim was to recruit a diverse range of older people and we were successful in some ways but not others. Thirteen were men and 8 women. They were aged between mid $50 \mathrm{~s}$ and late $80 \mathrm{~s}$. They included people living in their own homes, in sheltered housing and in hostels. Eleven lived on their own, 9 were married, 2 were single and the others were divorced, separated or widowed. We were not able to recruit any Black and Minority Ethnic (BME) older people, nor any lesbian, gay, bi-sexual, transexual (LGBT) older people. We did conduct a focus group with a group of Black older people that explored general views about alcohol use, rather than personal experiences.

The interviews adopted a broad structure within which to encourage people to talk. They started with a request to participants to describe their day to day life, then to consider what alcohol had meant to them in the past and its current place in their lives. Interviewees were then asked what impact alcohol had on their health, finances and relationships, whether they had ever sought help in relation to drinking and where they would go if they felt they needed help.

We undertook a thematic analysis, but also became aware as we did this that it was possible to identify different 'styles' of drinking amongst this group of older people. We start our presentation of findings by describing these.

\section{Drinking practices and styles}

We identified four different drinking styles that distinguish the ways in which people use alcohol, although do not necessarily reflect the amount that people drink.

Table 1 - Drinking styles

\begin{tabular}{|l|l|l|l|l|}
\hline Why & How often & Where & When & Who with \\
\hline $\begin{array}{l}\text { Style 1: Social - } \\
\text { regular }\end{array}$ & Every day & At home & Evening meal & Partner/spouse \\
\hline $\begin{array}{l}\text { Style 2: Social - } \\
\text { occasional }\end{array}$ & Variable & $\begin{array}{l}\text { Out / } \\
\text { friends / } \\
\text { home }\end{array}$ & $\begin{array}{l}\text { Part of meal/ } \\
\text { evening } \\
\text { out/social } \\
\text { gatherings }\end{array}$ & $\begin{array}{l}\text { Friends / } \\
\text { spouse }\end{array}$ \\
\hline $\begin{array}{l}\text { Style 3: Heavy } \\
\text { lone drinking }\end{array}$ & $\begin{array}{l}\text { Daily / } \\
\text { weekly }\end{array}$ & $\begin{array}{l}\text { At home / } \\
\text { pub / street }\end{array}$ & $\begin{array}{l}\text { All day/ during } \\
\text { the day/ evenings }\end{array}$ & On own \\
\hline $\begin{array}{l}\text { Style 4: Heavy } \\
\text { drinking in a } \\
\text { drinking }\end{array}$ & $\begin{array}{l}\text { Daily / } \\
\text { weekly }\end{array}$ & $\begin{array}{l}\text { At home / } \\
\text { pub / street }\end{array}$ & $\begin{array}{l}\text { All day/ during } \\
\text { the day/ evenings }\end{array}$ & $\begin{array}{l}\text { With friends } \\
\text { /other drinkers }\end{array}$ \\
\hline
\end{tabular}


network



Drinking style 1: 'Social - Regular'

For the regular social drinker alcohol was enjoyable and pleasurable. It was an experience that was shared with spouses or friends and contributed to the quality of relationships and to personal relaxation. Jane's ${ }^{1}$ account was typical:

It's probably beneficial... it's part of my relaxation after work and generally enjoyment. I tend to drink red wine ... and I think it's quite good for me allround ... definitely part of my relaxing and being at home process ... quality of life.

Angela emphasized the social characteristic of sharing a bottle of wine:

I wouldn't open a bottle for myself because it's a social thing. You have a glass of wine and you're talking... with my husband or when you're cooking.

Drinking style 2: 'Social - Occasional'

This style involved less frequent use of alcohol - it was not part of the everyday experience. In some cases this reflected a lifetime pattern whilst for others the style had evolved in response to other changes. Some people had reduced their use of alcohol as a result of health problems, others, including five people who lived alone, drank alcohol less frequently because the social context for this had changed. Sue explained how she had drunk more regularly before her husband died as it was something they did together. Her account reflects a shift from the context that Angela talked about:

There's something about it that feels like a return to a happier time in my life, do you know what I mean? ... when my husband was alive and it was something we could enjoy together, just sitting, having a meal and a glass of wine. And just having one always takes me back and I would think that that's probably quite important for a lot of people. It evokes a lot of memories of happier times.

\section{Drinking style 3: 'Heavy lone drinking'}

Several participants drank a lot and on their own - but for different reasons. One man liked to drink whisky, but couldn't afford to drink this in pubs; another had limited mobility and found it difficult to visit the pub. Individual biographies varied, but this drinking style also reflected both lifetime drinking patterns and responses to life changes. Katie's story demonstrates that it is not only those who live alone who

\footnotetext{
${ }^{1}$ Names have been changed to preserve anonymity
} 
drink alone. She lives with her husband and adult son but likes to drink a bottle of wine in the evenings:

I do not enjoy going out and meeting people, sitting in pubs and shouting at the top of my voice. When I come home, this is my haven, I want to be here. .... say if I had my friend come over, and she's very moderate, she drinks like a little... you know. So I feel embarrassed then. So l'd rather drink on my own.

Drinking style 4: 'Heavy drinking in a drinking network'

In contrast, the final style is one in which drinking a substantial amount of alcohol is either part of, or the reason for being with others. This was associated with drinking patterns that had been in evidence for much of interviewees' lives and all those who spoke of their drinking in this way were men. It typically involved drinking outside the home and friendships connected to the pub had played a large part in the lives of these men. This style was also evident amongst street drinkers, two of whom talked about the people they drank with in terms of comradeship and looking out for one another. Andy who lived in a hostel described his relationship with another resident:

...he's a right pisshead too, so he's my drinking buddy, know what I mean, and if I've got money I buy the booze, if he's got it he buys it, see I get paid fortnightly but he gets paid weekly so I carry him sometimes and then when I've no got it he carries me you know, tit for tat.

\section{What affects drinking styles}

Threaded through these different drinking styles were themes that highlight the complex relationships between individual biographies, personal circumstances and external factors affecting older people's use of alcohol.

\section{Social relationships}

For those who were regular or occasional social drinkers, as well as for heavy drinkers in a drinking network, alcohol was a part of their social life. Having a drink had positive associations with enjoyment, relaxation and leisure, as well as with a sense of camaraderie. But alcohol can also operate as a barrier to social life. Linda liked to have an active social life, but drank very little:

Yeah, when I meet friends in pubs they seem to, it's like smokers who like to be with smokers, it's a comradeship you know or camaraderie or whatever and the drinking is the same thing so it's almost like you've got to move out of that social group because you can't keep up with them.

Linda thought it was difficult to negotiate a social life without drinking in view of the dominance of drinking within British culture. 
Relationships amongst street drinkers were important not only for sociability, but also because they provided a sense of belonging, support and protection. But there were disadvantages to belonging to a network of drinkers. lan, a long-term heavy drinker who had cut down his drinking, felt he had to hide this from his drinking friends:

I'm trying to keep it quiet, I'm not even since the detox, I've only told certain people that I've come off the alcohol and the others, you know, I could still actually fool them, I could stand there with a coke and they'd think there's vodka in it and I think more fool you.

\section{Loss, change and adaptation}

Loss of partners, family and friends, as well as loss of physical health and mobility, daily routines and structures, were all identified in the context of alcohol use. Bereavement was acknowledged as a particularly difficult time during which alcohol may be a way of coping. After Lily was widowed she drank less than when her husband was alive, although in the immediate period after his death she was actively encouraged by a family member to have a drink to help her cope. She described how she would occasionally have a glass of wine as a 'pick-me-up':

If I am here on my own and I've been out and I'm cold, or something's triggered me off over my husband that's made me a little sad, I will get out a bottle.

Some of those who had drunk heavily over a long period also linked increases in their drinking to loss of loved ones. Andy traced the start of his heavy drinking to when his first wife died leaving him with three young children. Later in his life he had managed to stop drinking but started again after his brother was killed in an accident.

Life changes associated with loss of physical capacity were implicated in changes in drinking patterns. Tom would usually go for a pint after work and the pub was an important place of social contact. Following a fall he had difficulty walking and getting to the pub on his own. He had taken to having his daily couple of beers at home on his own; although he was waiting for an assessment for a mobility scooter which he hoped would enable him to get out again.

Toby and Larry were divorced, lived on their own and described how their drinking had increased on retirement. For Toby, this entailed going to the pub more often in order to socialise as well as drink, but Larry, who had been a taxi driver so unable to drink whilst he was working, drank at home.

Some of the women interviewed experienced retirement and growing older as a time when they were both freed from daily responsibilities of work and family, and had more disposable income that enabled them to enjoy social drinking. 
When we just moved here we had a huge mortgage and two young children we could not afford to have a bottle every day. If you have a young family you can't afford to go to the pub. (Christine)

\section{Cost and availability}

This latter point illustrates an important practical issue affecting older people's drinking patterns. Most of the regular social drinkers spoke about the affordability of wine as one reason why they could drink every day with their meal. In contrast, being on a low income affected infrequent social use of alcohol.

Cost also affected drinking practices of heavy drinkers. Andy said the amount that he drank completely depended on the amount of money he had to spend. lan linked an increase in his drinking to the time that supermarkets started selling cheaper alcohol:

You can go in the pubs and that and pay nearly 13 a pint, whereas you can go into an Asda's and buy it by the can load and it works out about 60p a pint.

He also noted the temptation to pick up cheap wine along with bread and milk in local convenience stores.

Health, well-being and growing older

Changes in lifestyle as a result of health issues affected drinking practices. Many of those who were taking medication had reduced the amount they consumed. Adjustment was affected by the place that alcohol had in their lives. For Ben, who had always been an occasional drinker, cutting out alcohol following a heart attack was not a problem. In contrast, those for whom alcohol had played a bigger part in their social activities, found adjustment more difficult. Mark responded to having had a stroke by mixing lager and water so he could continue to drink a substantial amount.

Bill, a heavy drinker most of his life, had a number of health problems, including diabetes, and responded by adjusting his medication:

You're not supposed to take certain pills when you're having alcohol so you work it ... so 8 hours ... you think am I going to have a drink today because I know so and so is coming round to see me so don't take those pills. You're alright for about 72 hours then after that you've really got to settle down again.

For others, worries over their health had been a motivating factor in making changes in drinking patterns. Ian decided to go for detox after a friend who also drank heavily was rushed into hospital. 
Those whose drinking practices fitted within the social styles of drinking did not feel that alcohol had negatively affected their health and many referred to a daily glass of red wine being recommended by doctors as good for the heart.

\section{Responsibility, control and independence}

Participants had made different decisions to control the amount of alcohol they consumed and many had their own self-imposed 'rules'. These included having only one drink a day, not drinking every day, not drinking before a certain time in the day or not drinking at home. For Linda this was affected by what she felt able to afford. She also thought it was important to find ways of keeping busy and enjoying herself that did not involve drinking. This was also about a responsibility to take care of herself. But she also identified the collective responsibility of government, the drinks industry and supermarkets to tackle alcohol problems and had found she occasionally drank more than she planned to because of special offers and cheap drinks.

Sue thought it was affected by decisions about how to spend time and what interests and activities to pursue in the face of growing older. Toby had initially increased his drinking after he retired, but changed his habits when he moved into sheltered housing and got involved in the organised activities on offer:

Because here you see people everyday and get to know people. And you don't feel the need to have a drink anyway, you know, not like I used to do.

\section{Seeking help}

Participants whose drinking practices fitted the social regular and social occasional styles had not sought help and did not think their drinking patterns required any help. Most thought that their GP (primary care physician) would be the first place they would go if they ever needed help.

Those whose drinking patterns fitted the two heavier drinking styles were ambivalent about seeking help. Some had made changes as a result of their GP's advice. Toby had responded to the doctor's advice and reduced his drinking without any further help:

My doctor hold me that if I didn't cut down on my drink and get my blood pressure down, I could have a stroke or a heart attack... she asked me how much a week do you drink, and I said something in the region of 21 pints and she said that's much too much.....

Some did not perceive their drinking as problematic, whilst others acknowledged that they were drinking above the recommended safe levels but reluctant to make any changes. Larry went for regular checkups and said his GP was aware of what he 
was drinking. He thought he might reduce the amount he drank if his GP strongly advised it. He enjoyed drinking, regarded it as one of his remaining pleasures and thought that life would be less enjoyable without it. Katie was aware that her drinking was above the recommended limit, but felt that this was her way of dealing with stress and worried that if she stopped drinking she would not be able to cope:

That might be the only place I feel happy, is from the drink, in a really rotten world, and lonely world. And you take that away......

When lan decided that he wanted to reduce his drinking he asked his GP to refer him for detox and said he was surprised that the GP hadn't suggested this to him before. He had tried AA meetings, but had found listening to long time members who had been dry for many years was off-putting. During and after the detox he had received one-to-one counseling and support which he had found helpful. Andy had made two unsuccessful attempts to detox and had also not found AA helpful. He found talking openly about his drinking and his behaviour within a group setting very difficult.

\section{Discussion}

In exploring a small sample of older people's drinking habits and the meaning of alcohol in their lives we have inevitably opened up wider questions about changes in quality of life as people age and some of the common issues which may be faced as a result of the passing of time. The stories people told about the place of alcohol in their life uncovered the impact of transitions through the life course and the adjustments and coping mechanisms which people access in order to retain some sense of continuity between the past and the present.

Clearly it is inadequate to conceptualise over use of alcohol solely as a health problem, but nor is it enough to bracket it as a welfare issue. It is perhaps more useful to understand older people's relationships with alcohol by reference to broader concepts of well-being, reflecting on the significance of older people's relationships with friends, family, strangers, the places in which they live and the norms and values of contemporary social relations. Our study suggests that policies which encourage community participation, and which facilitate social interaction, are inclusive, accessible and provide a range of means of social engagement, purpose and continuity for older people are all potentially helpful.

This is a topic that requires practitioners capable of engaging with an issue that is both complex and sensitive. It requires a dialogue between older people and practitioners which recognises the emotional, moral as well as material dimensions of their experiences. If health, social care, housing, voluntary sector and other practitioners are to be able to broach this sensitive issue with older people they are concerned about, this will demand engaging with factors fundamental to human 
well-being such as identity, relationships, continuity, hope, meaningfulness, purpose and belonging. This goes well beyond a focus on the impact alcohol may have on health and 'risky' behaviours, and an approach based in individual behaviour change.

But there is also a need for a broader perspective on the role of policy in this respect. We have seen how policies relating to cost and availability of alcohol can impact on older people's drinking. We might also anticipate that social and economic changes such as the need and expectation that people will continue in paid work for longer, or in contrast anxieties about being unable to do so, may have adverse effects. Whilst alcohol use is not inevitably a problem for older people, the problematic use of alcohol needs to be considered across the life course and from different policy perspectives.

\section{Implications for practice}

- Maintaining social spaces where older people can meet others and enjoy a drink together is likely to be important for many older people. Pubs that serve good food at reasonable prices can offer a focus for social contact and 'safe' drinking. The issue of the changing nature of pubs were raised by many and the extent to which they do not appear to be geared towards attracting the custom of older people. This is an issue that is relevant in the context of urban planning and regeneration.

- Having an active engagement in activities involving others plays an important mediating role for those who might be tempted to drink too much. The capacity to continue to take part in a range of social activities that engage older people's interests and skills could limit the likelihood that alcohol will be used to mask loneliness.

- Older people may need to be actively encouraged to take part in activities as they may be unused to mixing, having been used to being one of a couple in social situations for much of their lives. Low key facilitation and befriending schemes may be important here. Community development work encouraging older people's engagement is useful in relation to alcohol issues.

- This is a topic that has to be approached very sensitively but it is possible to create a context in which older people can talk about their drinking and this study has shown the value of enabling older people to tell their own stories about the place of alcohol in their lives.

- GPs are important as they were most likely to be identified as first source of help. An approach that is likely to be helpful cannot simply be framed in terms of 'safe units'. There is a need to understand the context in which drinking is occurring, the role it plays in older people's lives and what might be the consequences of stopping drinking. 
- Older people's rights to make their own decisions about how they live their lives needs to be balanced by an ethical approach that recognises vulnerable people may need help to determine how their needs might best be met. A process of dialogue with the older person concerned has the potential to enable the exploration of a difficult issue, and a shared decision-making approach to seeking solutions.

\section{References}

Barnes M and Taylor S (2007) Good Practice Guide. Involving Older People in Research: examples, purposes and good practice. ERA-AGE European Research Area in Ageing Research. Available at http://era-age.group.shef.ac.uk/content/228/ accessed 10 October 2008.

Clough R, Hart R, Nugent M, Fox D and Watkins C (2004) Older people and alcohol. A summary and recommendations arising from research in Ayrshire and Arran. Lancashire: Third Sector First.

Davidson K and Ginn J (2005) Problem Drinking and Older People. A report for the Joseph Rowntree Foundation. Centre for Research on Ageing and Gender, University of Surrey.

Department of Health (2004) Choosing Health: Making Healthier Choices Easier. London: Stationery Office.

Department of Health (2007) Safe Sensible Social: The next steps in the National Alcohol Strategy. London: Stationery Office.

Herring R and Thom B (1997a) 'The Right to Take Risks: Alcohol and Older People', Social Policy and Administration, 31 (3): 233 -246.

Herring R and Thom B (1997b) 'Alcohol misuse in older people: the role of home carers', Health and Social Care in the Community, 5 (4): $237-245$.

Johnson I (2000) 'Alcohol problems in old age: a review of recent epidemiological research', International Journal of Geriatric Psychiatry, 15: 575 - 581.

Klein W C and Jess C (2002) 'One Last Pleasure? Alcohol Use among Elderly People in Nursing Homes' Health \& Social Work, 27 (3): 193 - 203.

NHS Information Centre (2008) Statistics on Alcohol: England 2008. Available at http://www.ic.nhs.uk/pubs/alcohol08 Accessed 5 March 2009.

Peters R, Peters J, Warner J, Beckett N and Bulpitt C (2008) 'Alcohol, dementia and cognitive decline in the elderly: a systematic review', Age and Ageing, 37: 505 -512.

Plant M and Plant M (2008) Alcohol and Older People: a Review of Issues and Responses. Centre for Public Health Research: University of the West of England. 
Prime Minister's Strategy Unit (2004) Alcohol Harm Reduction Strategy for England. London: Cabinet Office.

Simpson M, Williams B and Kendrick A (1994) 'Alcohol and Elderly People: An Overview of the Literature for Social Work', Ageing and Society, 14 (4): 575 - 587.

Smith L and Foxcroft D (2009) Drinking in the UK: An exploration of trends. York: Joseph Rowntree Foundation.

Triggle N (2009) NHS treating more older drinkers.

[http://news.bbc.co.uk/1/hi/health/7922002.stm] Accessed 5 March 2009.

Ward L, Barnes M and Gahagan B (2008) Cheers!? A project about older people and alcohol. Available at http://www.brighton.ac.uk/sass/research/publications/ Accessed 3 March 2011.

Corresponding Author: Lizzie Ward, SSPARC, School of Applied Social Science, University of Brighton, Falmer, BN1 9PH. E.Ward@brighton.ac.uk 